\title{
Effectiveness of Physical Barriers Installation for Prevention of Incidents in Mexico City's Subway System
}

\author{
Gerardo de Jesús Portillo-Villasana, Aida Huerta-Barrientos, and Yazmin Dillarza Andrade \\ Department of Industrial Engineering and Operations Research, Faculty of Engineering, National Autonomous University of Mexico, \\ 04510 Mexico City, Mexico
}

Correspondence should be addressed to Aida Huerta-Barrientos; aida.huerta@comunidad.unam.mx

Received 21 February 2017; Accepted 24 May 2017; Published 18 June 2017

Academic Editor: Björn Johansson

Copyright (C) 2017 Gerardo de Jesús Portillo-Villasana et al. This is an open access article distributed under the Creative Commons Attribution License, which permits unrestricted use, distribution, and reproduction in any medium, provided the original work is properly cited.

\begin{abstract}
Nowadays, suicides inside the installations of subway platforms are considered a public health problem in Mexico City. One solution to prevent them is the installation of physical barriers, but their high cost is unattractive for governmental authorities. Traditional approaches of research on the effectiveness of physical barriers for preventing suicides have been limited to analyzing statistically the effects of installing platform screen doors and blue lights on subway platforms. Although considerable progress has been made in this field, many important issues remain unexplored. This study investigates the effectiveness of physical barriers installation for prevention of incidents in Mexico City subway system by means of an agent-based simulation model. Firstly, the design of physical barriers for prevention of incidents in Mexico City subway system is described. Secondly, a conceptual model of the Zócalo station subway platform is presented. Thirdly, an agent-based simulation model of Zócalo station subway platform is implemented using AnyLogic ${ }^{\mathrm{TM}}$ software considering normal operations of the subway station. This study shows that physical barriers installation on the Zócalo subway platform can effectively prevent $76 \%$ of passenger's suicides.
\end{abstract}

\section{Introduction}

Mexico City subway system (MCSS) started operating in 1961 and currently 12 lines serve the metropolitan area of Mexico City, including some municipalities in Mexico State. In 2015, the MCSS served 1.6 billion passengers placing it as the public transport preferred by citizens. In the last few years, an increase of the incidents in MCSS has been observed. According to the governmental authorities, while passengers are walking or running on the platform and cross the safety yellow line, they fall into the tracks, in some cases due to distraction, excessive and immoderate intake of toxic substances, and psychological problems. For instance, in 2014, at Copilco subway station (Line 3), a pair of friends were under the influence of alcohol, so one of them threw the other to the subway tracks while they were playing. No less important are the homicides or suicides considered as planned acts that cause, on the one hand, high operational costs and delays in conveyors scheduling and, on the other hand, psychological effects on conveyor's drivers and passengers $[1,2]$. Also fashion in social networks influences the incidents on the subway platform of MCSS.

Some years ago, a fashion trend called "jump the subway tracks" encouraged younger people to jump from subway platform to subway tracks. This kind of fashion had a big impact worldwide and was adopted by young people. Through some videos distributed via social networks, young passengers showed how others practiced the jump inviting others to perform them, which caused the adoption of such actions by others. Unfortunately, practitioners presented high risk to be involved in a mortal accident. As [3] explains, jumping the subway tracks is a behavior generated by young people who do not have access to education, who cannot get the access to university, or who do not get a satisfactory job. Following [3], it is so much the desire of young people to be noticed that is why they tend to try much more dangerous and risky things such as jumping the tracks of the train without considering the possibility of falling and receiving an 
electric shock that could be fatal. From 2010 to 2015, inside installations of MCSS, 84 men and 31 women committed suicide. The highest number of suicides was recorded in men whose ages ranged from 31 to 59 years, followed by men whose age ranged from 18 to 30 years, with 18 cases. Only 4 cases were committed by men over 60 years, 2 cases were men between 12 and 17 years old, and in 16 cases the age was not specified. With respect to suicides committed by women, in 15 cases the women's age ranged from 31 to 59 years, in 7 cases the age ranged from 18 to 30 years, in 5 cases the age was not specified, in 2 cases the age ranged between 12 and 17 years, and in 2 cases women were more than 60 years old. In this period, the associated costs for each suicide reached $\$ 500,000$ dollars.

According to [4], the suicide is considered a public health problem in Mexico City because it has increased by $400 \%$ since the 1970s. In this country, the reasons provoking suicide are, for example, nervousness or mental imbalance, painful illness, and economic or sentimental problems. In Hong Kong, most attempters of railway suicide are unmarried psychotic young men under psychiatric care having a high level of lethal intent [5]. In [6], the relationship between hours of sunlight and railway suicide attempts was assessed. The study was conducted at Tokyo, Kanagawa, and Osaka prefectures in Japan. In this case, less sunlight in the 7 days leading up to the railway suicide attempts was associated with a higher proportion of attempts.

On the one hand, in [7], it was shown that there has been a constant focus on suicide prevention and only relatively recent interest in trespass countermeasures. On the other hand, an interesting review research on railway suicides to inform suicide prevention initiatives and future studies, including who is at risk and why and behaviors at track locations, can be found in [8]. As is well-known, countries around the globe such as England, France, Hong Kong, Japan, Singapore, and Taiwan have managed to install platform screen doors (PSDs) and blue lights on subway platforms as effective ways for accidents and suicide prevention $[2,5]$. In this direction, [9] pointed out that the calming effect of blue lights installed at the ends of railway platforms in Japan reduced suicides by $84 \%$. In this case, governmental data listing all railway suicide attempts in Japan from April 2002 to March 2012 were used to investigate the proportion of suicide attempts within station premises, where blue lights are potentially installed, and at night, when they would be lit. In the last decade, the effectiveness of physical barriers for preventing suicides has received considerable attention among scholars. For instance, [5] examined the effectiveness of installing PSDs for preventing railway suicides and any sign of substitution of suicide location; and changes in the psychiatric profile of suicide deceased after the PSD installation in the subway system of Hong Kong. The effectiveness of installing PSDs was assessed through a quasi-experimental setting. Poisson's regression and chi-squared test were used. A significant reduction of 59.9\% $(p=0.0003)$ in railway suicides was found after the PSD installation.

In the case of transfer facilities in developing countries, the operational efficiency and safety of a subway station are also affected by the service capabilities and matching degree.
Interesting results of a traffic investigation are shown in [10]. In this case, the service facilities were classified within a subway station considering service objects, service forms, service functions, and several other features to analyze the pedestrian behavior and pedestrian flow.

In addition, the weaving area may be also a critical risk place in the subway transfer station as is shown in the study presented in [11]. In this case, the high density weaving pedestrian was studied based on statistical results, for instance, the passenger velocity, the walking distance, and the journey time. It was noticed that the walking pedestrians were influenced by the weaving conflict and tend to change the direction of movement to avoid the conflict in weaving area.

A review of more recent studies considering the flow of pedestrian inside the subway station includes [12, 13]. For instance, in [12], it is shown that the weekday and the weekend patterns in terms of the spatiotemporal flow of size distributions of passengers in subway networks influence directly the performance of interactions between transfer and nontransfer stations. In fact, the substantial trends have roughly the same form, with noticeable lower sizes on weekend being ascribed to the essential characteristics of travel demand. While, in [13], a simulation-based dynamic passenger assignment framework and models were proposed in the context of schedule-based rail transit system. In the simulation framework, passengers as well as trains were modeled as individual agents who were able to obtain complete information on the current traffic conditions. In this case, more than 0.8 million individual passengers and thousands of trains were simultaneously simulated.

Research on the effectiveness of physical barriers for preventing suicides has been limited to analyze statistically the effects of installing platform screen doors (PSDs) and blue lights on subway platforms. The traditional approaches have been statistical correlation and regression. Although considerable progress has been made in this field considering additional aspects, such as service capabilities and matching degree, flow of passengers, high density weaving pedestrians, and flow of pedestrians, many important issues remain unexplored. Our intention is to investigate the effectiveness of physical barriers installation for prevention of incidents in MCSS by means of an agent-based simulation model. We consider that this study may contribute towards a better understanding of physical barriers as an effective device for preventing accidents on subway platform using simulation modeling. Simulation is the imitation of the operation of a real-world process or system over time that many managers are incorporating to test designs without committing resources to acquisition [14].

This study is divided into five main sections. Firstly, the design of physical barriers for preventing fatal incidents in Mexico City's subway system is described. Secondly, the conceptual model of the Zócalo station subway platform, including the flow chart of incidents, is presented. Thirdly, an agent-based simulation model of Zócalo station subway platform is implemented using AnyLogic software. Finally, the discussion of the effectiveness of physical barriers installation on Zócalo station subway platform is carried out. 


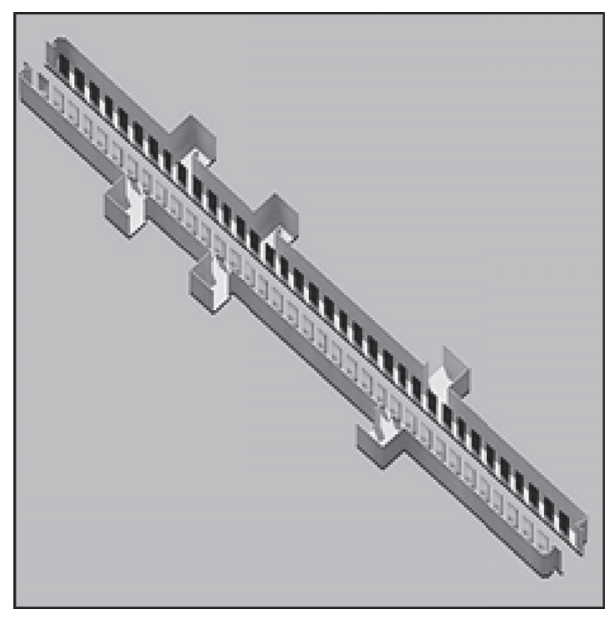

FIgURE 1: The design of physical barriers.

\section{Designing Physical Barriers to Prevent Fatal Incidents on the Subway Platform}

The use of screens to prevent incidents on the subway platform is a solution that involves structures. The structures can be static over time, since they have the same function as the antisuicide barriers and only a small section is open to allow the movement of passengers from the convoy. The entire length of MCSS's stations is approximately 150 meters. The physical barriers proposed could be deployed throughout the subway platform, leaving free spaces at the location of the convoy's doors (see Figure 1). When the convoy arrives to the subway platform, it has no defined location so, at each arrival, the convoy presents variations in its stop point. We observed this situation during 1 month. With respect to a reference fixed point, the convoy arrives at this point $\pm 30 \mathrm{~cm}$.

If any person for any cause bumps it with one of his or her extremities, either the head, torso, or foot, sensors distributed along the physical barriers warn the user of its current state of risk (see Figure 2). It should be noted that installing more sensors would produce a more integrated barrier. In order to design the infrared barrier, we selected the infrared transmitter and receiver. It was also necessary to identify the type of electronic device suitable for processing the information.

An incident can be considered as a discrete event, so the physical barriers must be able to identify this type of event. When referring to a discrete circuit, we associate electronic circuit composed by discrete components, such as resistors and transistors, whose states are on/off. Transistors are comprised of three parts: the manifold, the emitter, and the base. This device is used for integrated circuits and electronic arrangements to control, for instance, hearing and visual devices. As is shown in Figure 3, the gate 74L32 is an OR logic gate that expresses its false result, if only its two inputs are false, while the gate M74HC4072 is also an OR gate and performs the same logic as its predecessor, only with the difference that its logic is used by four inputs and gives a false result only if all four inputs are false, and the gate $74 \mathrm{LS} 125 \mathrm{~A}$ is an inverter gate that has four independent doors

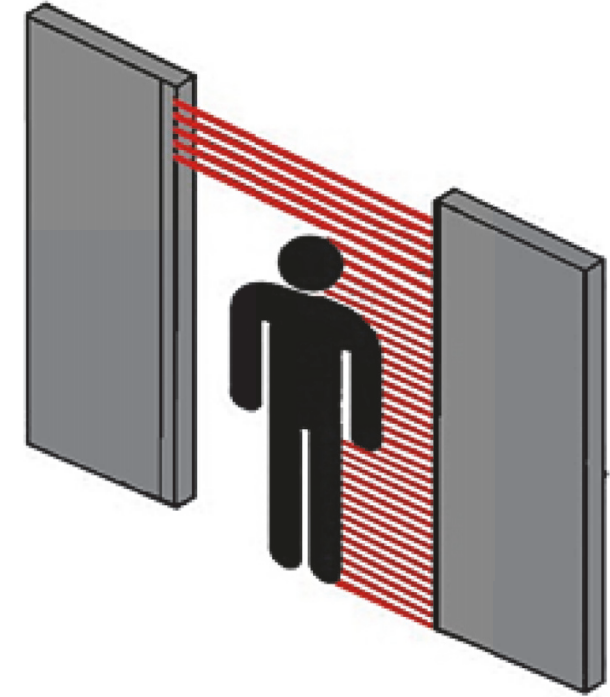

FIgURE 2: Conceptual diagram of an infrared barrier.

of which each one carries out an inverting damping function. The outputs have 3 states. When the output is activated, it is called low impedance. When it is deactivated, its output is deactivated with high impedance. This device processes and delivers a signal that is sent to both a hearing device and a visual signal, to help passengers pay attention, while they are walking on the subway platform. All these components allow developing the concept of electronic device which meets the primary need which is to warn the users of the alert state due to lack of precaution when located in an area considered unsafe while waiting for the arrival of the convoy to the subway platform.

\section{The Conceptual Model of Zócalo Station Subway Platform}

In this study, we consider the Zócalo subway station that is a station of Line 2 of the MCSS. The Zócalo station operates 365 days per year, from 5 a.m. to 12 p.m. on working days, from 6 a.m. to 12 p.m. on Saturdays, and from 7 a.m. to 12 p.m. on Sundays and holidays. Figure 4 illustrates subway passengers awaiting the conveyors while crossing the safety yellow line in Zócalo station. The extension of the station platform is 147.2 meters.

The Zócalo station is a transit station geographically located between the Allende and Pino Suárez subway stations, at the center of Mexico City. Figure 5 shows the conceptual model of the Zócalo subway station. We consider two main agents, passengers, and convoys. Passengers arrive to the subway platform and select a physical location while awaiting the arriving train (see Figure 5 left side). It is important to note that, during peak hours on Monday through Friday, the subway platforms are separated into two sections; as of October 4, 2007, the mayor of the Mexico City launched The "Zero Harassment" program, which includes the allocation of the four first trains to women, children under 12, and people with different capacities. On the other hand, the entrance to 


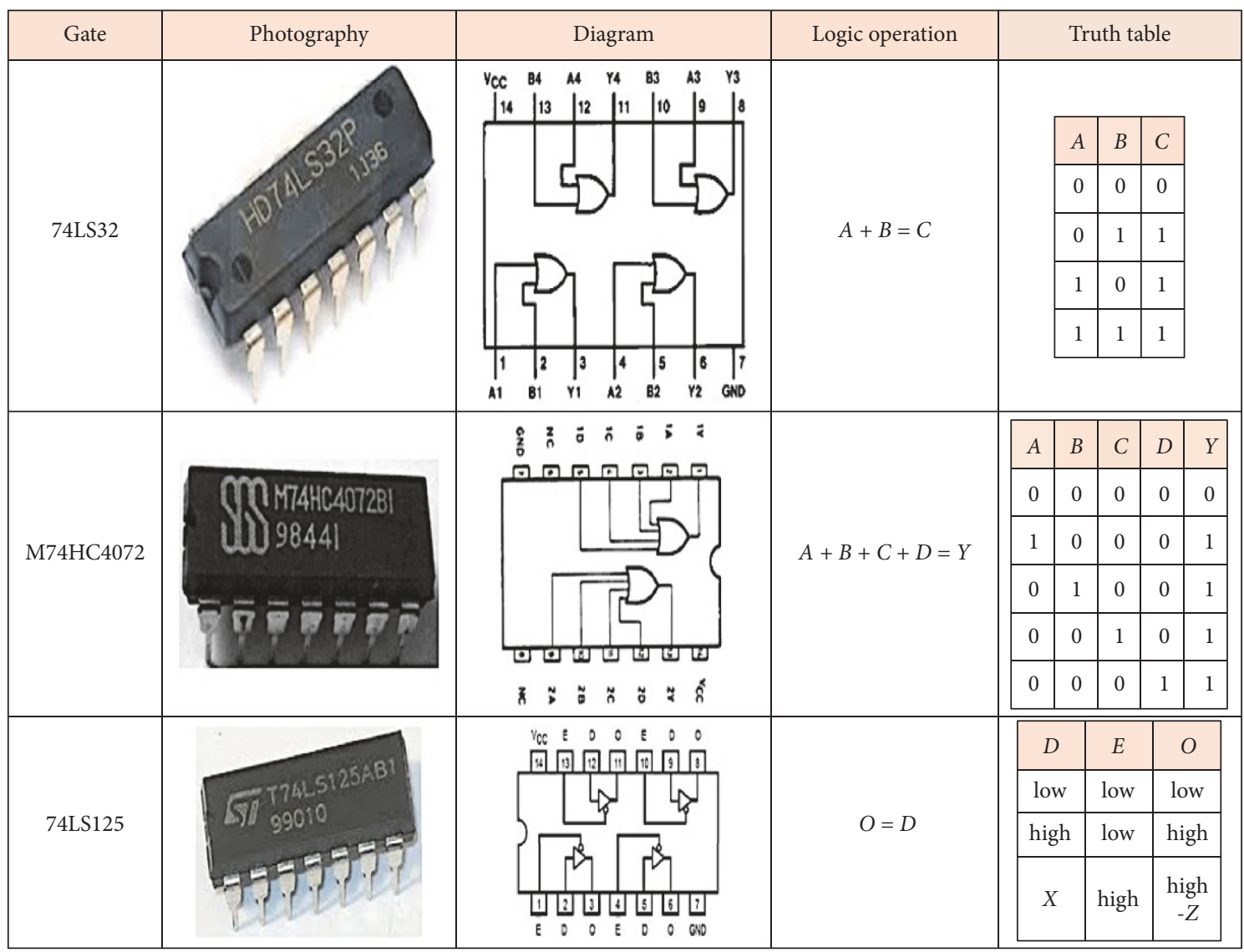

Figure 3: Diagram, logic operation, and truth table of logic gates.

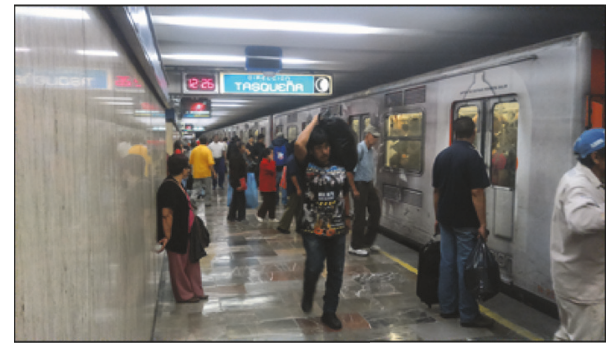

Figure 4: The flow of passengers on the subway platform of Zócalo station.

the train system (right side of Figure 5) occurs when it is set in motion to reach the Zócalo station, for which the convoy consists of nine trolleys, when approaching. The input of the Zócalo station moderates the braking speed.

When the convoy stops, it proceeds to the opening of doors. While the doors are open, passengers and the convoy interact. However, these activities are carried out without any coordination. So while passengers who have arrived at their final destination try to leave the convoy, passengers who are on the subway platform try to board the convoy, at the same time. Due to the limited capacity of convoys, passengers waiting on the platform may or may not ascend to the convoy. If not, repeat the actions of choosing a location on the platform, wait for the next convoy, and try to ascend again. During this process, it is important to note that the yellow security line is not respected. The process ends when passenger ascends the convoy and the doors are closed.

\section{The Simulation Model of Zócalo Station Subway Platform}

4.1. The Simulation Software. The conceptual model of the Zócalo subway station platform including the physical barriers is implemented in computer using AnyLogic Personal Learning Edition release 7.3 which is well-known generalpurpose simulation software that takes advantage of Java programming language. For the purpose of this study, we used two libraries included in AnyLogic: the Pedestrian and the Rail libraries. The AnyLogic Pedestrian library supports the simulation of pedestrian flows in a virtual environment creating models of pedestrian buildings like subway stations, security checks, streets, and so forth [15]. The Pedestrian library supports 3D animation [16]. The AnyLogic Rail library supports accurate modeling and simulation of rail aspects such as dimensions of individual cars, exact topology of tracks and switches, and acceleration and deceleration of trains. In this way, the simulation models implemented using such library are of very high performance [16]. This library also supports both 2D and 3D animation of tracks, switches, 


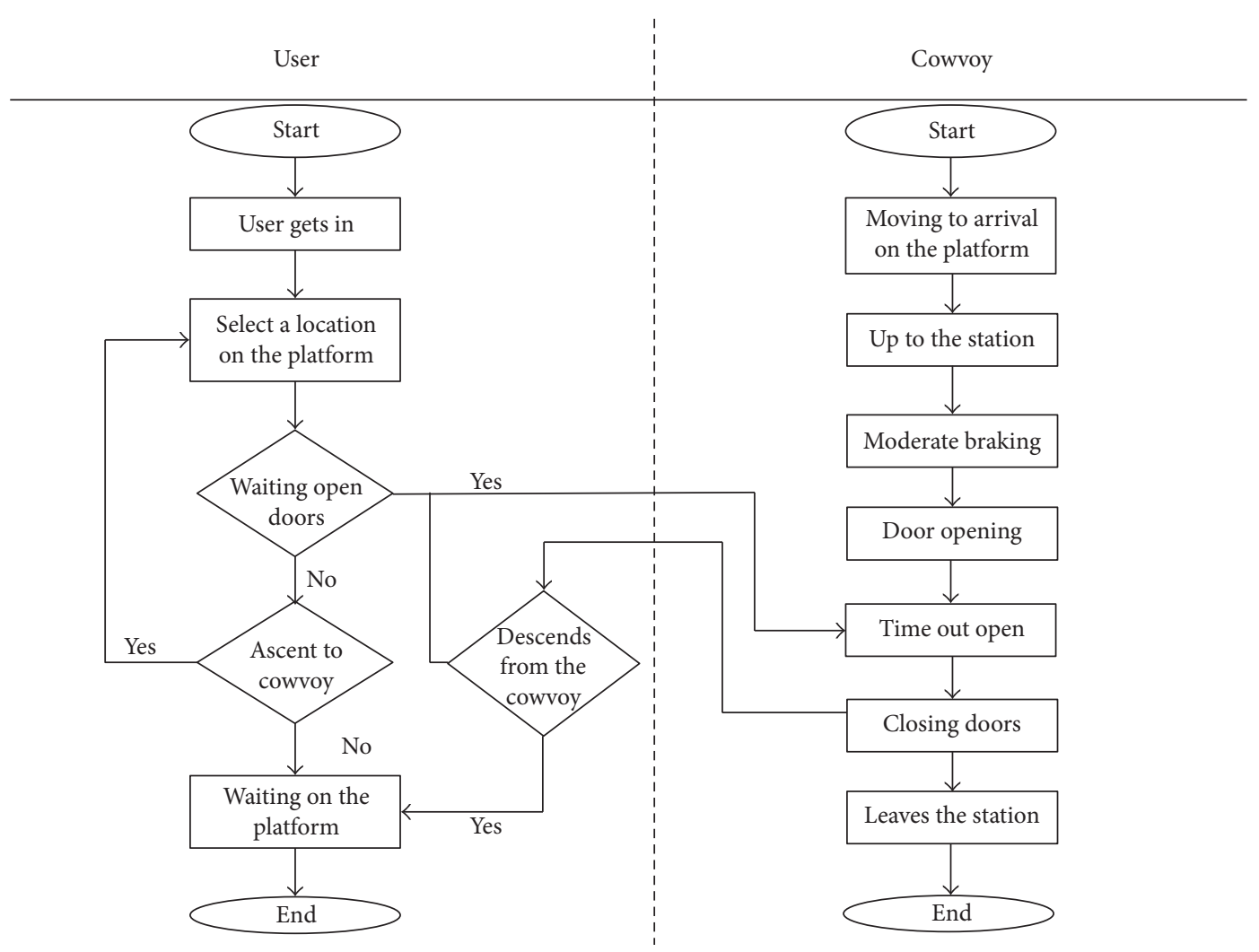

FIgURE 5: The conceptual model of the Zócalo station subway platform.

and rail cars. The simulation model implemented for the purpose of this study was created with $3 \mathrm{D}$ animation.

4.2. Input Data Analysis. Data on the number of passengers entering to the subway platform per minute and the interarrival time of convoys were collected during three months, one hour in a daily basis. We used the Stat::Fit Standard software release 3.0.1.0, developed by Geer Mountain Software [17], to fit the appropriate probability distribution to the number of passengers entering to the subway platform per minute and the interarrival time of convoys. In the two cases, the negative binomial distribution was given as the best fit. In general, negative binomial distribution describes the probability of $k$ failures and $r$ successes in $k+1 \operatorname{Bernoulli}(p)$ trials with success on the last trial; see (1). Table 1 shows the values of $r$ and $p$ parameters.

$$
\operatorname{NegBin}(r, p)
$$

4.3. The Simulation Model. As seen in Figure 6, the layout of Zócalo subway platform was designed considering real physical dimensions. Zócalo station has two directions: towards Tasqueña and Cuatro Caminos. The subway tracks were traced among the subway platforms.

4.4. Simulation Model Verification. According to [18], the simulation model verification is defined as ensuring that the computerized model and its implementation are correct. Following [14], the animation is a very useful verification
TABLE 1: Parameter values of the negative binomial distribution.

\begin{tabular}{lcc}
\hline Negative binomial distribution & $r$ & $p$ \\
\hline Passengers per minute, towards Cuatro Caminos & 73 & 0.797 \\
Passengers per minute, towards Tasqueña & 14 & 0.461 \\
Interarrival time of convoys, towards Cuatro Caminos & 7 & 0.037 \\
Interarrival time of convoys, towards Tasqueña & 23 & 0.130 \\
\hline
\end{tabular}

tool. In this study, while running the simulation model, using 3D animation, we detected some actions that firstly were illogical, mainly related to the passenger's movements along the subway platform. Additionally, all inconsistent error warnings detected by the internal debugger included in AnyLogic software were solved.

4.5. Simulation Model Validation. As suggested by [18], a model is considered valid for a set of experimental conditions, if its accuracy is within its acceptable range, which is the amount of accuracy required for the model's intended purpose. In this study, to validate the simulation model implemented, we conducted a sensitivity analysis to validate that the simulation model represents the dynamic of passengers in the Zócalo subway platform. As shown in Table 2, the passenger comfortable speed was varied from a low value to a high value.

We run the simulation model taking into account the two values for the passenger's comfortable speed. In the first 


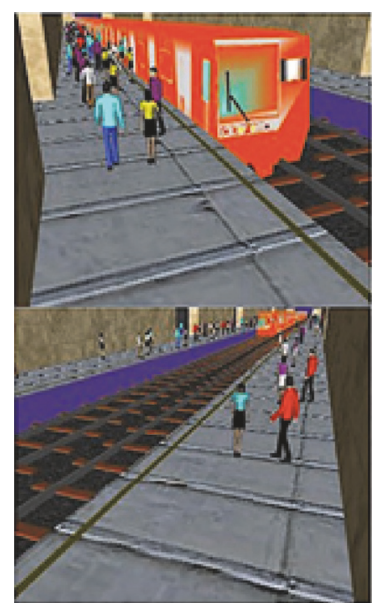

(a)

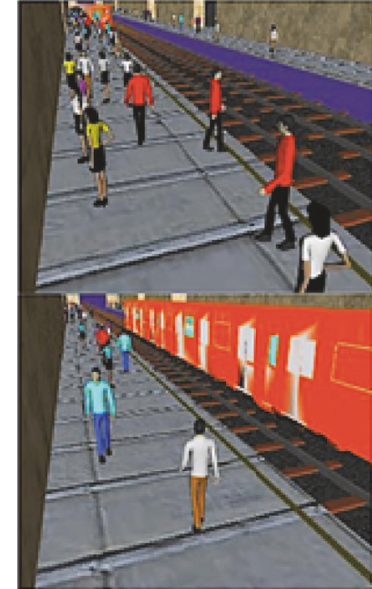

(b)

Figure 6: Simulation model of the Zócalo subway station (a) towards Tasqueña and (b) towards Cuatro Caminos.

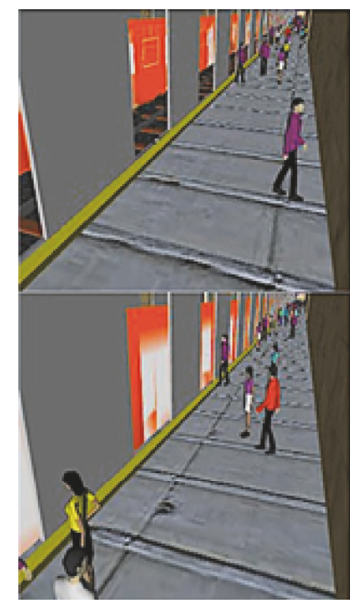

(a)

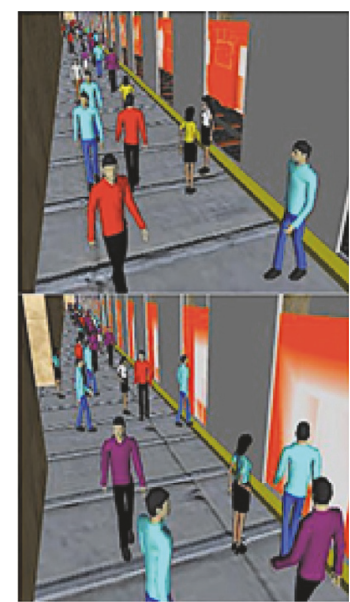

(b)

FIGURE 7: Simulation model of the Zócalo subway station considering the installation of physical barriers (a) towards Tasqueña and (b) towards Cuatro Caminos.

TABLE 2: Values for the passenger's comfortable speed.

\begin{tabular}{lcc}
\hline Simulation model input variable & Low $\left[\mathrm{ms}^{-1}\right]$ & High $\left.^{-1} \mathrm{~ms}^{-1}\right]$ \\
\hline Passenger's comfortable speed & Uniform $(0.0,0.5)$ & Uniform $(0.5,1.5)$ \\
\hline
\end{tabular}

case, when the passenger's comfortable speed was low, the passenger's density on the subway platform, shown in the simulation model, was very high. On the contrary, when the passenger's comfortable speed was at a high level, the passenger's density on the subway platform was very low. We observed these two situations also when we visited the subway installations. So, we consider that the simulation model accuracy is within its acceptable range to represent the dynamic of the Zócalo subway station platform.

\section{Analysis of the Effectiveness of Physical Barriers Installation in Subway Platform}

In order to analyze the effectiveness of physical barriers installation, we included them virtually into the simulation model as shown in Figure 7. Then, randomly the intention to commit suicide was induced to the passengers represented by the agents in the simulation model. We executed 100 simulation experiments to observe the behavior of passengers. 


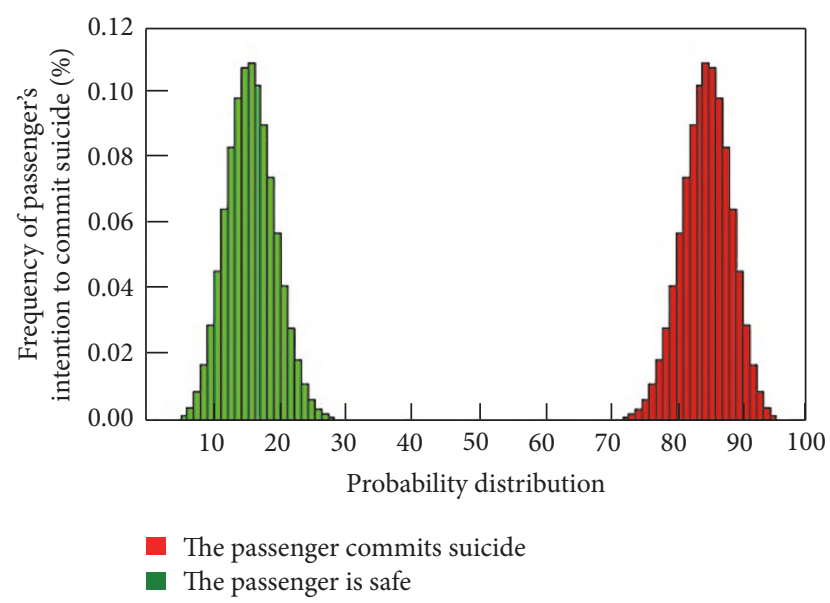

FIGURE 8: Histogram of suicide without the installation of physical barriers.

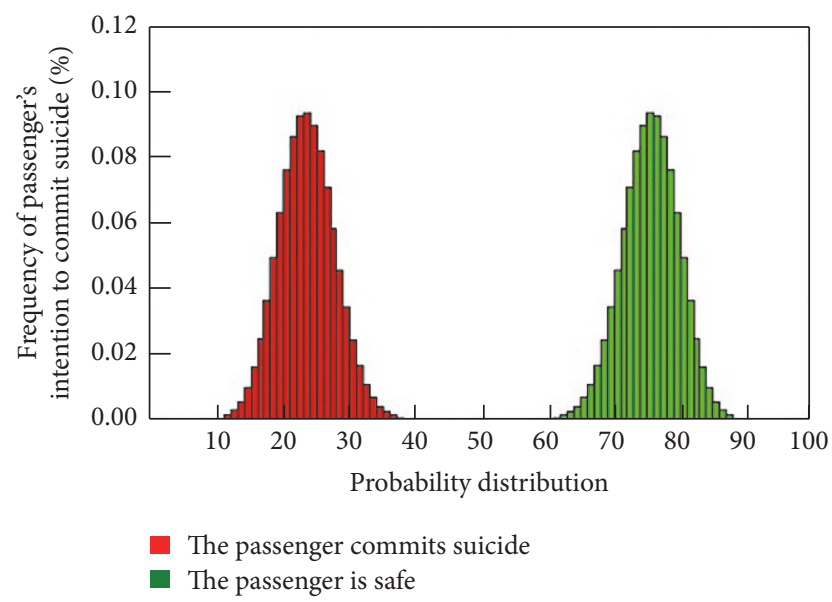

FIGURE 9: Histogram of suicide considering the installation of physical barriers.

On the one hand, as Figure 8 illustrates, $84 \%$ of subway passengers who have the intention to commit suicide reach their objective without the installation of physical barriers, while the $16 \%$ are safe despite their intention. On the other hand, as Figure 9 shows, considering the use of physical barriers, $24 \%$ of subway passengers who have the intention to commit suicide reach their objective, while $76 \%$ were saved because the physical barriers safeguard them. Also, the rest of passengers, those who were not induced to commit suicide, remained waiting for the train behind the installed physical barriers until the convoy arrives, so the incidents were reduced. Finally, the physical barriers contributed to the free flow of passengers avoiding congestion points because passengers preferred empty secure areas.

\section{Conclusion}

We proposed the development of an agent-based simulation model to quantify the effectiveness of the installation of physical barriers to reduce the rate of suicides committed on the subway platform stations of Mexico City subway system. Through the simulation model, we imitated the operation of the real Mexico City subway system to test the solution for preventing suicides previously to the real implementation. We considered two simulation scenarios. The first one simulated the behavior of passengers and their interactions with the convoys, without physical barriers, so the rate of suicides was $84 \%$. On the contrary, on the second simulation scenario, considering the installation of physical barriers, the rate of suicides was just $24 \%$. We consider that the simulation results from this study may support the decision-making process of governmental authorities of Mexico City about the installation of physical barriers on the subway platform for saving lives of citizens whose emotional conditions cause suicide.

\section{Conflicts of Interest}

The authors declare that there are no conflicts of interest regarding the publication of this paper.

\section{Acknowledgments}

This study was partially supported by the National Council for Sciences and Technology of Mexico (CONACYT).

\section{References}

[1] C. Cothereau, C. de Beaurepaire, C. Payan, J. P. Cambou, F. Rouillon, and F. Conso, "Professional and medical outcomes for French train drivers after "person under train" accidents: three year follow up study," Occupational and Environmental Medicine, vol. 61, no. 6, pp. 488-494, 2004.

[2] Y. W. Chung, S. J. Kang, T. Matsubayashi, Y. Sawada, and M. Ueda, "The effectiveness of platform screen doors for the prevention of subway suicides in South Korea," Journal of Affective Disorders, vol. 194, pp. 80-83, 2016.

[3] AMAPSI, "Eduardo Murueta Reyes," http://www.amapsi.org.

[4] J. García, Un joven cae a la vía, permanece 20 minutos sin sentido y salva la vida pese a pasarle el metro por encima, 2015, http:// www.elcorreo.com/bizkaia/margen-derecha/201505/03/heridotras-caer-vias-20150503104849.html.

[5] C. K. Law, P. S. F. Yip, W. S. C. Chan, K.-W. Fu, P. W. C. Wong, and Y. W. Law, "Evaluating the effectiveness of barrier installation for preventing railway suicides in Hong Kong," Journal of Affective Disorders, vol. 114, no. 1-3, pp. 254-262, 2009.

[6] H. Kadotani, Y. Nagai, and T. Sozu, "Railway suicide attempts are associated with amount of sunlight in recent days," Journal of Affective Disorders, vol. 152-154, no. 1, pp. 162-168, 2014.

[7] G. M. Havârneanu, J.-M. Burkhardt, and F. Paran, "A systematic review of the literature on safety measures to prevent railway suicides and trespassing accidents," Accident Analysis and Prevention, vol. 81, article no. 3784, pp. 30-50, 2015.

[8] B. L. Mishara and C. Bardon, "Systematic review of research on railway and urban transit system suicides," Journal of Affective Disorders, vol. 193, pp. 215-226, 2016.

[9] M. Ichikawa, H. Inada, and M. Kumeji, "Reconsidering the effects of blue-light installation for prevention of railway suicides," Journal of Affective Disorders, vol. 152-154, no. 1, pp. 183185, 2014. 
[10] L. Y. Yao, L. S. Sun, W. H. Wang, and H. Xiong, "Adaptability analysis of service facilities in transfer subway stations," Mathematical Problems in Engineering, vol. 2012, Article ID 701852, 12 pages, 2012.

[11] L. Sun, Z. Yang, J. Rong, and X. Liu, "Study on the weaving behavior of high density bidirectional pedestrian flow," Mathematical Problems in Engineering, vol. 2014, Article ID 765659, 9 pages, 2014.

[12] J. Feng, X. Li, B. Mao, Q. Xu, and Y. Bai, "Weighted complex network analysis of the different patterns of metro traffic flows on weekday and weekend," Discrete Dynamics in Nature and Society, vol. 2016, pp. 1-10, 2016.

[13] X. Yao, B. Han, D. Yu, and H. Ren, "Simulation-based dynamic passenger flow assignment modelling for a schedule-based transit network," Discrete Dynamics in Nature and Society, vol. 2017, pp. 1-15, 2017.

[14] J. Banks, Handbook of Simulation: Principles, Methodology, Advances, Applications, and Practice, John Wiley and Sons, New Jersey, NJ, USA, 1998.

[15] AnyLogic, http://www.anylogic.com.

[16] A. Borshchev, The Big Book of Simulation Modeling: Multimethod Modeling with Anylogic 6, AnyLogic North America, Illinois, Ill, USA, 2013.

[17] J. C. Benneyan, "Software Review: Stat::Fit. OR/MS Today," 1998, http://lionhrtpub.com/orms/orms-2-98/swr.html.

[18] R. G. Sargent, "Validation and verification of simulation models," in Proceedings of the 1999 Winter Simulation Conference Proceedings (WSC), pp. 39-48, December 1999. 


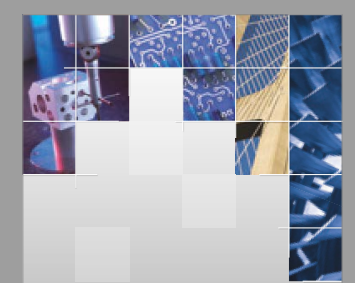

\section{Enfincering}
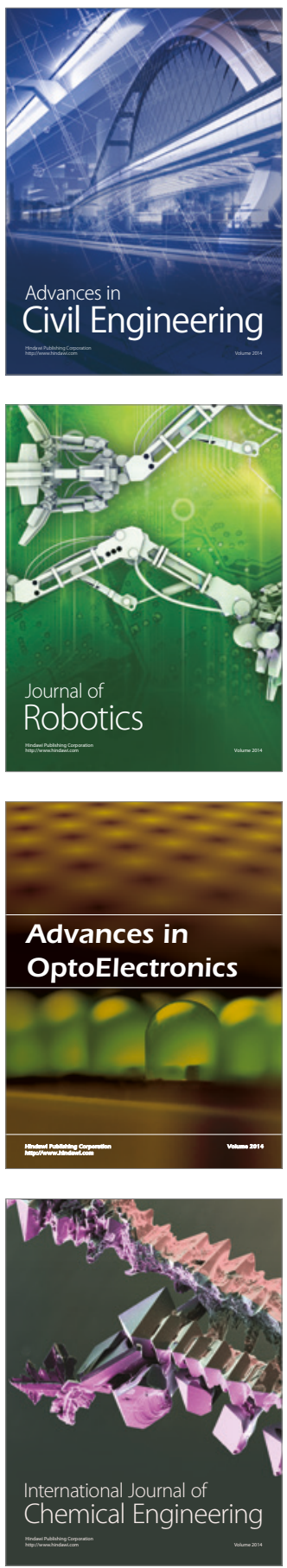

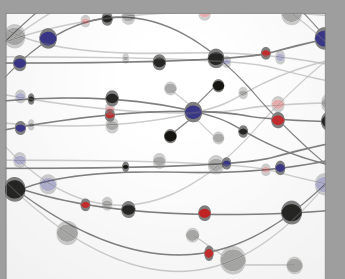

The Scientific World Journal

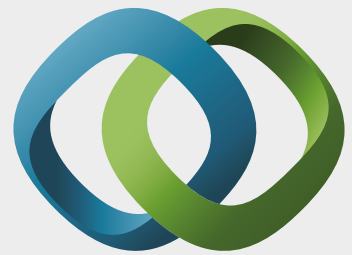

\section{Hindawi}

Submit your manuscripts at

https://www.hindawi.com
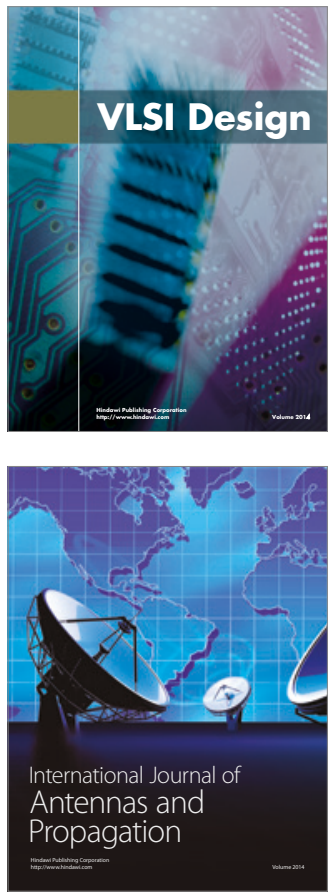

\section{Rotating}

Machinery
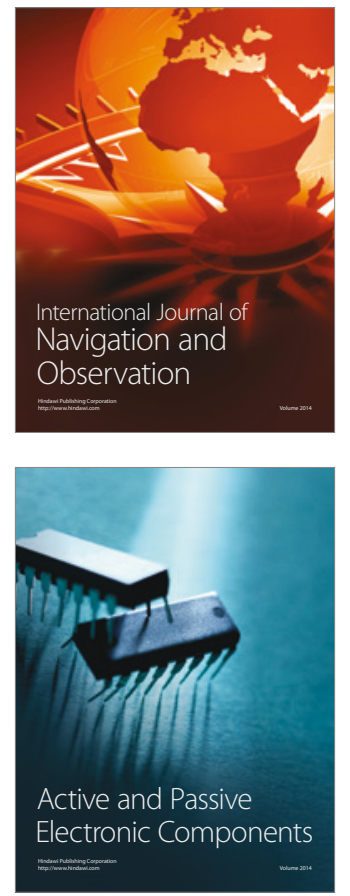
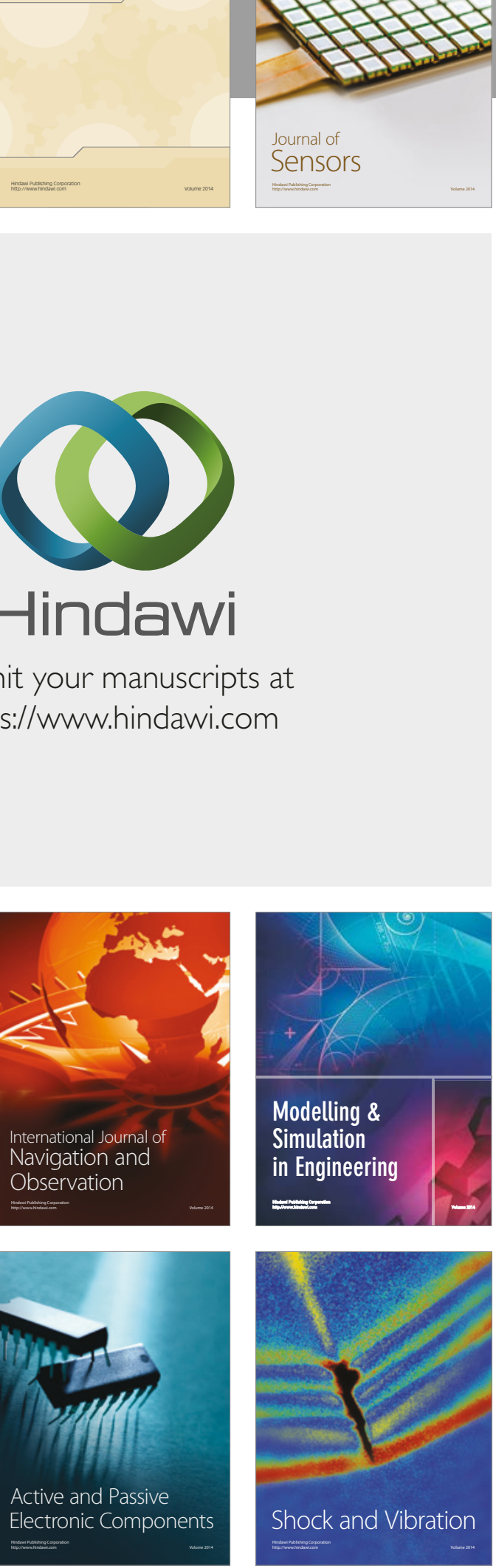
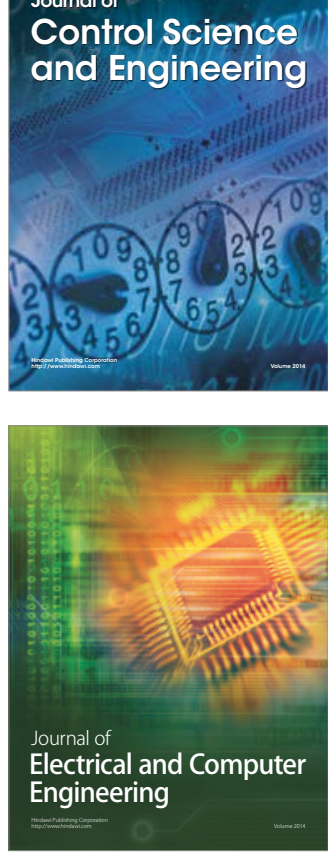

Distributed

Journal of

Control Science

and Engineering
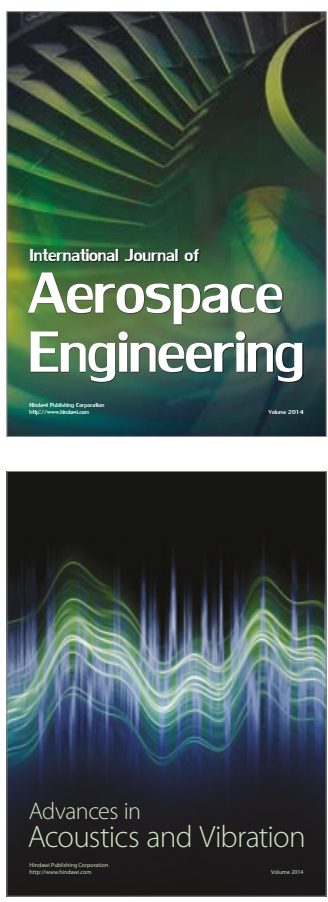

Sensor Networks 